\title{
O ENSINO DA LEITURA E DA ESCRITA EM LÍNGUA PORTUGUESA MEDIADO PELA LITERATURA DE CORDEL NA E. E. M. VIRGÍLIO TÁVORA NA CIDADE DE BARBALHA-CE.
}

THE TEACHING OF READING AND WRITING

IN THE PORTUGUESE LANGUAGE MEDIATED BY

E. E. M. VIRGÍLIO TÁVORA CORDEL LITERATURE

IN THE CITY OF BARBALHA-CE.

\section{Rafaelly Carneiro dos Santos Nogueira' Verinha Alderina Leite ${ }^{2}$ Josier Ferreira da Silva}

1 Mestranda do Mestrado Profissional em Educação da Universidade Regional do Cariri (URCA), professora de língua portuguesa da rede pública estadual do Ceará (SEDUC-CE).

2 Mestranda em Letras - Programa de Pós-Graduação em Letras - Universidade Regional do Cariri (URCA). Especialista em Prática Docente do Ensino Superior/Educação, Planejamento e Políticas Públicas - Faculdades Integradas de Patos-PB. Língua Portuguesa - Universidade Regional do Cariri. Gestão Escolar - Universidade do Estado de Santa Catarina-UDESC.

3 Pós-doutor em Educação pela Universidade Federal da Paraíba - UFPB. Doutor em Educação Brasileira pela Universidade Federal do Ceará - UFC e Professor do departamento de geociências da Universidade Regional do Cariri- URCA e do Programa de Pós-Graduação em Educação da URCA- campos Crato-CE. 
RESUMO: O presente estudo pretende apresentar a importância da literatura de cordel para o ensino da leitura e escrita em língua portuguesa no ensino médio, através do relato de uma experiência metodológica exitosa realizada na E. E. M. Virgílio Távora, na cidade de Barbalha, no Cariri cearense. Referenciando-se em pesquisas de autores que utilizam os folhetos de cordel como objeto de estudo, com destaque para Melo (1982) e Galvão (2002). Recorreu-se também à legislação educacional vigente, a LDB nº9394/1996 e a atual Lei no $13.415 / 2017$ sobre o novo ensino médio. Na análise dos resultados, percebemos que a produção do cordel propiciou maior interação entre os escolares e foi vista como forma descontraída de ler e escrever além de aliar conhecimento ao contexto cultural da cidade de Barbalha-Ce.

PALAVRAS-CHAVE: Literatura de Cordel; Leitura; Escrita; Barbalha.

ABSTRACT: This study aims to present the importance of the Cordel Literature in the teaching reading and writing in the Portuguese language discipline in high school, based on the report of a successful methodological experiment carried out at E. E. M. Virgílio Távora, in the city of Barbalha, in Cariri (Ceará). This work referrers to research by authors who use cordel leaflets as the object of study, with emphasis on Melo (1982) and Galvão (2002). It was also resorted the current educational legislation, LDB No. 9394/1996 and the current Law No. 13,415 / 2017 about the new high school. In the analysis of the results, we noticed that the production of the cordel provided greater interaction of the students and it was seen as a relaxed way of reading and writing in addition to combining knowledge with the cultural context of the city of Barbalha-Ce.

KEYWORDS: Cordel Literature; Reading; Writing; Barbalha. 


\section{INTRODUÇÃO}

A literatura de cordel, importante expressão cultural do Brasil, sobretudo para o Nordeste, constitui-se de narrativas em versos do cotidiano popular com linguagem simples, valorizando a oralidade e a descrição detalhada dos fatos contados. A tradição da literatura de cordel sempre fez parte da vida de muitos nordestinos, fato que se deve às distintas características sociais e culturais da região.

Melo (1982) aponta para alguns desses fatores, como a organização de sociedade patriarcal, o surgimento de formações messiânicas, o cangaço, a seca e seus consequentes distúrbios econômicos e sociais, entre outros fatores, contribuindo para o surgimento de cantadores como instrumento do pensamento coletivo, nas manifestações da memória popular. Essa adaptação contribuiu para a utilização dos "folhetos" na alfabetização de uma grande massa popular.

No entanto, hoje se evidencia a falta da literatura popular nos contextos pedagógicos das escolas, nas salas de aula como instrumento de ensino da leitura, escrita e interpretação de textos, nas aulas de literatura ou de forma interdisciplinar. Percebemos a ausência de valorização por parte dos professores na utilização dessa ferramenta em sala de aula, contribuindo para o aumento do preconceito já existente na sociedade em relação a esse gênero literário dentro e fora do espaço escolar.

Assim, considerando a rica e comprovada contribuição da literatura de cordel como "prática de letramento" (GALVÃO, 2002, p.116) e de leiturização, e da necessidade de novas metodologias de ensino aprendizagem na contemporaneidade, o nosso trabalho busca relatar as contribuições da literatura de cordel para o desempenho leitor de alunos do $1^{\circ}$ ano do ensino médio da E. E. M. Virgílio Távora, na cidade de Barbalha, localizada na região do Cariri, no sul do Ceará.

Mesmo cientes da necessidade da leitura para a produção e aquisição de conhecimento, entendemos que, além da leitura, a educação deve transcender o universo crítico dos estudantes. Assim, trataremos da relevância do cordel no ensino da língua portuguesa, considerando o contexto da cidade de Barbalha-CE, "celeiro cultural" da região do Cariri, e da escola em estudo.

Dessa forma, o desejo de socialização dessa prática concretiza-se na análise 
dos resultados obtidos com os estudos e oficinas desenvolvidos durante o projeto e na utilização do cordel produzido pelos alunos, servindo para despertar o interesse pela leitura de outros discentes. Um trabalho pautado no "aprender a aprender" de forma crítica em relação aos temas que envolvem a sociedade. Ou seja, uma leitura e interpretação do mundo a partir do conhecimento e produção da literatura de cordel.

\section{LITERATURA DE CORDEL, LEITURA E LEITURIZAÇÃO}

As relações interativas entre o leitor e o texto devem ocorrer de forma prazerosa e significativa, de modo que o leitor seja encaminhado à prática leitora. A leitura de obras literárias favorece o dinamismo que falta nas aulas de leitura no cotidiano escolar e é uma forte aliada para diversificar os gêneros textuais e aguçar o gosto de ler.

Segundo Silva (2003), os textos literários têm espaço e relevância no processo de leiturização quando são bem escolhidos e as atividades bem planejadas, atendendo aos interesses dos alunos.

A leitura institucionalizada, realizada para avaliar os estudantes, usada como forma imposta de escolarização está cada vez mais em desuso. Na contemporaneidade, exigem-se novas estratégias de leitura, que dialoguem com a realidade dos educandos.

As atividades devem ser bem planejadas, alinhadas com as leituras propostas para que realmente possam contribuir na ampliação desse universo, no sentido do multiletramento, aproximando o leitor de sua realidade. Nesse sentido, a literatura de cordel é um gênero textual que pode ser utilizado com maior frequência, pela linguagem simples, acessível e ainda descontraída.

A relação entre esses elementos pode ser percebida quando o professor, em sala de aula, relata a importância e as contribuições da literatura, fornecendo ao texto literário uma nova visão, o que resulta na aceitação pelos escolares, firmando uma aliança entre leitor, texto e professor. Isso propicia e fortalece a formação de leitores proficientes e satisfeitos, fruto do encanto e proximidade com a vida dos educandos. O professor terá um leque de abordagens a utilizar com seus escolares, e se torna cada vez mais eficaz quando envolve o aluno em seu contexto socioemocional e histórico (Silva, 2003). 
O trabalho com o texto literário proporciona práticas socializadoras, nesse sentido Todorov , menciona:

A literatura pode muito. Ela pode nos estender a mão quando estamos profundamente deprimidos, nos tornar ainda mais próximos dos outros seres humanos que nos cercam, nos fazer compreender melhor o mundo e nos ajudar a viver. Não que ela seja, antes de tudo, uma técnica de cuidados para com a alma; porém, revelação do mundo, ela pode também em seu percurso, nos transformar a cada um de nós a partir de dentro. (TODOROV, 2009, p.76)

Silva (2003) corrobora quando menciona que a literatura pode ser uma forte aliada, em se tratando do processo de leitura e leiturização, com o qual os escolares podem evoluir na compreensão leitora de forma proativa trazendo leveza ao ato de ler.

Segundo Silva (2003), não é fácil estreitar as relações entre leitura, literatura e escola, mas é preciso repensar a concepção de leitura norteadora da prática pedagógica, bem como reavaliar a própria noção de literatura apresentada para os alunos a partir das atividades desenvolvidas em sala de aula.

Assim, a escola precisa repensar e replanejar as ações, no sentido de firmar uma interconexão entre literatura, leitura e escola de modo mais eficaz, abrindo espaço para novas perspectivas, pautadas no "aprender a aprender", "aprender a conhecer" e "aprender a fazer", (Diretrizes Curriculares Nacionais Gerais da Educação Básicas, 2013), numa abordagem sociointeracionista. Sobre isso, a Base Nacional Comum Curricular elaborou 10 (dez) competências gerais, dentre elas destacamos, aqui, a seguinte: "Agir pessoal e coletivamente com autonomia, responsabilidade, flexibilidade, resiliência e determinação, tomando decisões com base em princípios éticos, democráticos, inclusivos, sustentáveis e solidários", (BNCC, 2017, p. 12). Isso nos convoca a assumir um novo olhar sobre o ensino e aprendizagem com leitura, impulsiona repensar sobre a inserção de novas estratégias pedagógicas.

Diante das competências específicas de linguagens e suas tecnologias para o ensino médio, destacamos a seguinte competência da BNCC (2017):

Apreciar esteticamente as mais diversas produções artísticas e culturais, considerando suas características locais, regionais e globais, e 
mobilizar seus conhecimentos sobre as linguagens artísticas para dar significado e (re)construir produções autorais individuais e coletivas, exercendo protagonismo de maneira crítica e criativa, com respeito à diversidade de saberes, identidades e culturas. (BNCC, 2017, p. 49).

Isso remete ao contexto interdisciplinar e transdisciplinar que a literatura e a literatura de cordel podem assumir mediante às necessidades individuais e coletivas do leitor quando se depara com o texto, o hipertexto e seus aspectos multisemióticos e pragmáticos, num processo intrínseco de saberes culturais e históricos. Nisso se inclui a habilidade dos escolares a ser desenvolvida e atingida com autonomia de:

Expressar-se e atuar em processos de criação autorais individuais e coletivos nas diferentes linguagens artísticas (artes visuais, audiovisual, dança, música e teatro) e nas intersecções entre elas, recorrendo a referências estéticas e culturais, conhecimentos de naturezas diversas (artísticos, históricos, sociais e políticos) e experiências individuais e coletivas, (BNCC, 2017, p. 498).

A referida habilidade reflete-se na maneira bakhtiniana de enxergar o dialogismo existente entre o que se ensina e o que se aprende na escola e na vida real, vivências, experiências dos escolares, como bem coloca Silva (2003), quando remete à literatura e a classifica como "força humanizadora", no sentido de agir em prol da sua ação formativa e transformadora.

O processo de leiturização deve ocorrer na escola de forma dinâmica e de modo que as responsabilidades pela prática da leitura e também da escrita sejam de forma tripartite no âmbito escolar: docente-discente-escola, tornando-se coletivos em suas estratégias e tomadas de decisões para seguir de formas síncronas aos diálogos sobre as práticas de leitura na escola e, especificamente, na sala de aula

\section{O CORDEL NA SALA DE AULA- RELATO}

O cordel, desde a sua difusão pelo Brasil, tendo como ponto de partida o nordeste, sempre significou uma forte expressão da cultura. A literatura de cordel sempre 
foi um importante instrumento de comunicação escrita e leitora, uma vez que enfatiza a vida cotidiana e diversos assuntos de interesse da população em geral. Isso porque a linguagem coloquial, que muitas vezes se assemelha aos trejeitos da fala, torna-se acessível aos públicos de diferentes classes sociais e escolaridades.

Partindo dessa premissa, em nosso trabalho, temos o homem como o ser de transformação social e cultural, considerando suas diferentes formas de participação na cultura com reflexos para a vida pessoal e coletiva, sobretudo no ambiente escolar. Nesse contexto, a forte relação entre cultura e educação se entrelaça permitindo a utilização de metodologias plurais e criativas ao ensino de leitura e escrita, como o cordel.

Nesse viés, Paulo Freire define cultura "como todo resultado da atividade humana, do esforço criador e recriador do homem, do seu trabalho por transformar e estabelecer relações de diálogo com outros homens" (FREIRE, 1982, p. 45). Percebemos, aqui, que a produção do homem é essencial para a "educação libertadora" que o autor propõe, uma educação que leva à percepção de si e de estar no mundo e de agir em sociedade de forma crítica e livre. Assim, nossa discussão acerca da relação entre cultura e educação se confirma na fala de Ribeiro (2018):

O ato educativo, que pressupõe sujeitos em busca da autonomia, é eminentemente social. As diferenças entre seus diversos atores [...] os aproximam. Relacionando-se primeiramente uns com os outros através das didáticas e das metodologias do fazer pedagógico, sua relação essencial é, em sua essência política, e se concretiza no complexo campo de gravidade do universo da cultura. (RIBEIRO, 2018, p. 3).

Diante do exposto e tendo em vista o panorama atual da educação básica brasileira, seus desafios e percalços para obtenção da qualidade no processo ensino-aprendizagem contemporâneo, enfatizamos o ensino de língua portuguesa, historicamente abalizada como uma das disciplina que possibilita uma maior autonomia individual e coletiva, uma vez que trata da compreensão da língua materna, essencial para as demais aprendizagens. Conforme as Orientações curriculares para o ensino médio:

Procura-se, dessa maneira, demonstrar a relevância dos estudos As ações realizadas na disciplina Língua Portuguesa, no contexto do 
ensino médio, devem propiciar ao aluno o refinamento de habilidades de leitura e de escrita, de fala e de escuta sobre a produção de sentido em práticas orais e escritas de uso da língua - e, mais amplamente, da linguagem -, em diferentes instâncias sociais; consequentemente, será apontada a importância de se abordarem as situações de interação considerando-se as formas pelas quais se dão a produção, a recepção e a circulação de sentidos. (BRASIL, 2006)

Recentemente, o "novo ensino médio", proposto pela Base Nacional Comum Curricular- BNCC, Lei no $13.415 / 2017$, aponta para um ensino organizado em itinerários formativos e disciplinas obrigatórias, como a língua portuguesa. Reforça a necessidade de inovação leitora, por meios digitais e modernos, mas sem deixar de considerar o texto literário no convívio dos estudantes.

Como linguagem artisticamente organizada, a literatura enriquece nossa percepção e nossa visão de mundo. Mediante arranjos especiais das palavras, ela cria um universo que nos permite aumentar nossa capacidade de ver e sentir. Nesse sentido, a literatura possibilita uma ampliação da nossa visão do mundo, ajuda-nos não só a ver mais, mas a colocar em questão muito do que estamos vendo/ vivenciando. (MEC, 2017, p. 67)

Voltamos nosso olhar, enquanto professoras da área de linguagens, ao ensino da língua materna que compreende as relações sociais e culturais apresentadas nesse novo milênio, um ensino contextualizado no aprender fazendo, no cotidiano dos estudantes e nas novas propostas pedagógicas que venham a promover e tornar a leitura um momento prazeroso e de socialização com a cultura.

\section{ASPECTOS INICIAIS}

A ideia de inserção do cordel em sala de aula surgiu, inicialmente, após a realização da avaliação diagnóstica do nível de proficiência em língua portuguesa, com destaque nas habilidades de leitura e escrita dos alunos do $1^{\circ}$ ano do ensino médio. A avaliação é realizada por meio da participação e do desempenho dos educandos 
no decorrer das aulas no início do ano letivo, no primeiro bimestre, pelos professores da área de linguagens e códigos e pela Secretaria de Educação do Ceará (SEDUC), com questões que contemplam a leitura e a escrita.

Essa avaliação justifica-se como uma prática de acompanhamento dos alunos desde a sua inserção na nova escola até o final do seu percurso escolar nessa etapa de ensino. A LDBEN/96 toma o ensino médio como etapa final da educação básica, uma fase de estudos que pode ser compreendida como o período de consolidação e aprofundamento de muitos dos conhecimentos construídos ao longo do ensino fundamental. (LDBEN, 1996, P. 123)

Aqui, recorreu-se ao diálogo como estratégia humanizadora de aprendizagem que, na perspectiva de Paulo Freire (1987) é fundamental para uma educação como prática de liberdade. O cordel foi a ponte de ligação entre os alunos e a escola. Uma metodologia dialógica conhecida entre os jovens da região, o que possibilitou a aproximação das histórias de vida dos estudantes às comunidades, permitindo relacioná-las a problemas sociais que dizem respeito à sociedade em geral.

\section{O CONTEXTO DO ESTUDO}

Barbalha-CE é um município formado por diversas manifestações culturais, herdadas de um processo de povoamento que orientou a projeção da formação dos núcleos urbanos em interatividade política e social com expressões culturais do catolicismo popular, cultuadas nas localidades de origem dos precedentes.

A cidade situa-se no entorno da Chapada do Araripe, na confluência dos sertões do Ceará, Pernambuco, Paraíba e Piauí. Na língua dos índios Cariris significa "lugar onde nasce o dia". É uma cidade com forte cultura, com destaque para os grupos de brincantes, a religiosidade, o artesanato e a gastronomia. Anualmente tem, nos festejos ao padroeiro Santo Antônio, uma das maiores festas do nordeste brasileiro: "A Festa do Pau da Bandeira de Santo Antônio".

Além das expressões da cultura imaterial, ela também se faz presente na materialidade da cidade, integrada por sobrados, casarões que se constituem ponto de 
apoio da memória, como expressão simbólica e social da sua construção histórica. Dentre essas manifestações, destaca-se a "Festa do Pau da Bandeira de Santo Antônio", importante símbolo identitário da cultura local, reconhecida como patrimônio imaterial nacional pelo Instituto do Patrimônio Histórico e Cultural Nacional-IPHAN, desde 2015, a qual integra os festejos alusivos ao padroeiro Santo Antônio, na tradicional Festa de Santo Antônio de Barbalha-CE.

No âmbito da literatura de cordel, a cidade possui a Sociedade dos Poetas de Barbalha-SPB, fundada em 17 de setembro de 2010, com 24 poetas associados, que atuam promovendo e otimizando a cultura popular, como a literatura de folhetos e outros trabalhos literários.

Nesse contexto, observa-se o rico espaço cultural em que a E.E.M. Virgílio Távora está inserida. A instituição, fundada em 4 de maio de 1964, atualmente presta serviço educacional à comunidade barbalhense em dois turnos de funcionamento, na modalidade de ensino regular e presencial. A escola atende, em sua maioria, a alunos de baixa renda familiar e em vulnerabilidade social, com origens em bairros periféricos e da zona rural da cidade. Conforme o Projeto Político Pedagógico (PPP):

Os alunos chegam à escola, muitas vezes, sem a preparação necessária para o nível a que foram promovidos, o que cristaliza os baixos índices de aprendizagem, e não raro, favorece a evasão escolar. Além dessa problemática da deficiência na aprendizagem, outro fator que leva à evasão escolar é o êxodo dos jovens a outros municípios em busca de empregos. (PPP,2018, p-8)

A realidade social e cultural dos estudantes implica no baixo desempenho de aprendizagem e aponta para a necessidade de projetos e ações dinâmicas que aliem a realidade dos estudantes ao espaço escolar, no sentido de produzir mudanças positivas na comunidade e contribuir para formação integral dos educandos. 


\section{METODOLOGIA}

O desenvolvimento do projeto ocorreu por meio de oficinas. Inicialmente foi apresentado o cordel, escrito e declamado, para que os alunos se familiarizassem com esse tipo de literatura. As primeiras oficinas abordaram diversos temas sociais e culturais de interesse dos estudantes, a história do cordel no Brasil e suas contribuições para o nordeste, suas possibilidades de leitura e de produção.

Na sequência, houve duas oficinas para estudos voltados sobre cordelistas da região do Cariri e da Barbalha, os quais tratavam de assuntos e lugares com os quais os alunos facilmente se identificaram. A linguagem fácil e fluída permitiu maior interação e leitura dos folhetos, criando um clima harmonioso e prazeroso para debates e interpretações.

A estrutura estilística do cordel foi tratada de forma dialógica por meio de comparativos que os próprios alunos ditavam, após a realização frequente dos cordéis. Também houve momentos de conversa e recital por meio da visita de cordelistas conhecidos da comunidade e membros da Sociedade de Cordelista do Cariri, quando os poetas falaram da sua relação pessoal com a poesia de cordel e de suas inspirações.

Ao final de cinco encontros, a turma escolheu um tema para a produção de um cordel, tendo sido escolhido por unanimidade a corrupção no Brasil, com ênfase para o atual cenário discursivo do mensalão. Assim, nossa atuação foi de mediadoras da aprendizagem e produção de conhecimento dos estudantes. Eles próprios decidiam, em coletividade, como conduzir as pesquisas sobre o assunto, a definição e a divisão entre as estrofes, bem como a organização para a tiragem dos cordéis e a confecção de camisetas para o recital de apresentação do cordel produzido.

Ao longo de 15 oficinas, que ocorreram no laboratório de informática da escola, com duração de 15 hora/aula, no período de quatro meses, de agosto a novembro de 2015, outras atividades foram desenvolvidas, sendo todas devidamente registradas, por alunos do projeto e professores responsáveis, em um portfólio. Dentre essas atividades destacamos:

- Apresentação e leitura de diversos folhetos de cordel; 
- Discussões acerca de diversos temas atuais;

- Roda de conversa com cordelista da cidade de Barbalha-CE;

- Recital de poesia entre os alunos e professores convidados;

- Interpretação de texto por meio da leitura de cordéis;

- Pesquisas digitais direcionadas;

- Estudo sobre poetas renomados da cultura popular, como Patativa do Assaré;

- Produção de um cordel intitulado "Corrupção no Brasil”

\section{SUJEITOS}

Participaram do projeto de oficinas de cordel, alunos do $1^{\circ}$ ano do ensino médio da E.E.M. Virgílio Távora do ano letivo de 2008, selecionados mediante resultado de avaliação diagnóstica interna e externa, realizadas respectivamente pelos professores de língua portuguesa da referida escola e pela SEDUC-CE.

Nesse sentido, voltou-se o olhar para aqueles alunos que obtiveram menor índice de desempenho nas habilidades de leitura e escrita, constituindo um universo de 25 alunos participantes com faixa etária entre 14 e 16 anos do turno vespertino. A escolha do horário para atuação das oficinas considerou as estatísticas de rendimento escolar, sendo esse o período com maior índice de evasão e de baixo desempenho de aprendizagem em língua portuguesa.

Outro fator considerado é que $65 \%$ dos alunos que estudam no turno da tarde são de diversas comunidades da zona rural da cidade, e seus familiares ou responsáveis, em sua maioria, agricultores ou trabalhadores em atividades agropecuárias e domésticas. Quanto aos aspectos de escolaridade familiar, muitos também não concluíram o ensino fundamental ou não foram alfabetizados, repercutindo na importância e valorização que os educandos atribuem à escolarização e aprendizagem. 


\section{AS CONTRIBUIÇÕES DO CORDEL PARA A LEITURA E ESCRITA}

As contribuições do cordel para a leitura são percebidas logo nos primeiros momentos do estudo. Os alunos reconhecem nesse tipo de literatura uma familiaridade na linguagem coloquial e, mesmo com o pouco contato com essa literatura na escola e como instrumento de aprendizagem, muitos se mostraram conhecedores das características elementares à classificação do cordel como narrativas próprias da cultura brasileira.

Os alunos puderam trabalhar a oralidade, vocabulário e entonação necessários para a declamação de cordel que difere da poesia romântica e das leituras em prosa que estavam acostumados a realizar rotineiramente. Embora a literatura de cordel seja tida como erudita, a proposta trouxe empolgação e vontade de conhecer os poetas populares por meio de seus contos e cantos. Podemos dizer que o ensino da língua materna, na disciplina de língua portuguesa, tendo como ferramenta de ensino o cordel, será sempre atual por tratar de temas cotidianos e de interesse social. Acrescenta Melo (1982)

A literatura de cordel é tudo isso e muito mais. É acontecimento da cultura brasileira que vem sendo questionada em universidades no País e no exterior -, em simpósios, seminários, conferências em nossos centros culturais. Há vivo interesse pelo cordel na própria chamada opinião pública, que acompanha, paralelamente, o que ocorre no País e no mundo através dos folhetos ou na apresentação dos contadores pela televisão, no noticiário do dia a dia. (Melo, 1982, p.9)

A mediação ocorrida entre os sujeitos da pesquisa e a literatura popular revelou que os alunos conheciam tradicionalmente o cordel associado à oralidade, por meio de grupos que, por muito tempo, foram alvos de preconceito linguístico e social. O trabalho com o cordel permitiu a reelaboração de saberes a partir dos que já existiam, proporcionando maior segurança nas leituras que são propostas em sala de aula e, consequentemente, na escrita.

Outro resultado observado foram as diversas formas de leitura que o cordel 
permitiu desenvolver. Sendo um dos primeiros pontos a serem percebidos, a relação leitor e ouvinte, como pontua Galvão(2002):

Vários estudos realizados no campo da história da leitura têm mostrado que as próprias situações de leitura determinam a produção de sentidos nos processos de usos e apropriações dos impressos: um mesmo texto, lido em voz alta ou silenciosamente, de maneira intensiva ou extensiva, produz significados diferentes para seus leitores (GALVÃO, 2002, p.119)

Observou-se o despertar dos alunos ao protagonismo estudantil mediada pela autonomia exercida pelos sujeitos no decorrer das oficinas. A coletividade criou um espaço de cumplicidade e aprendizado leitor e do mundo, permitindo ao indivíduo penetrar o âmbito da alteridade sem perder de vista sua subjetividade e história. $O$ leitor não esquece suas próprias dimensões, mas expande as fronteiras do conhecido, que absorve através da imaginação e decifra por meio do intelecto (ZILBERMAN, 2008, p. 10).

\section{CONSIDERAÇÕES FINAIS}

Percebeu-se que a literatura de cordel, utilizada na sala de aula, é uma experiência significativa, tanto para os escolares, quanto para o docente em Língua Portuguesa, uma vez que propiciou momentos de estudos, pesquisas e construção do conhecimento de forma envolvente e favoreceu a interatividade, a criatividade e expressividade dos escolares.

Nesse sentido, diante das novas propostas educacionais impostas ao país e de seu atual contexto político e de desigualdade cultural, fica evidente a necessidade de abordagem do tema de forma interdisciplinar, que deve acontecer para além do que se propõem os novos currículos. Confirmando a definição de Paulo Freire (1987):

a interdisciplinaridade é o processo metodológico de construção do conhecimento pelo sujeito, com base em sua relação com o contexto, com a realidade, com sua cultura. Busca-se a expressão inter- 
disciplinaridade pela caracterização de dois movimentos dialéticos: a problematização da situação, pela qual se desvela a realidade, e a sistematização dos conhecimentos de forma integrada. FREIRE (1987).

Observou-se, durante a realização do projeto, que as atividades desenvolvidas contribuíram para a exploração das relações sociocognitivas e emocionais dos estudantes envolvidos, de modo que o protagonismo juvenil e o desenvolvimento da competência leitora se fortaleciam a cada ideia surgida, a cada imaginação sobre o mundo real ou fictício, a cada informação nova e a cada construção realizada no âmbito da escrita do cordel.

Sendo assim, concluimos que o desenvolvimento de projetos de valorização da cultura popular, aliados a estratégias de ensino de interesse dos envolvidos, é apresentado como uma forma de abordagem da teoria libertadora de Paulo Freire, também chamada de Educação Popular, justificada por uma educação que visa conhecer a cultura do povo e desfazer os paradigmas históricos e culturais que envolvem os temas geradores das lutas populares. Soma-se a isso a concepção que a maioria de educadores e educadoras têm em relação ao papel da educação, como forma de minimizar parte das mazelas e das desigualdades sociais do país.

No tocante à leiturização, talvez o problema esteja desde a formação inicial fragmentada de professores à ausencia de formações continuadas articuladas com o contexto sociocultural de cada docente e de cada escola, o que tem limitado a capacidade dos alfabetizadores para "leiturizar". Para a pesquisadora argentina Lerner (2002, p. 17),

[...] ensinar a ler e a escrever é um desafio que transcende amplamente a alfabetização em sentido estrito. $O$ desafio que a escola enfrenta hoje é o de incorporar todos os alunos à cultura do escrito, é o de conseguir que todos os seus ex-alunos cheguem a ser membros plenos da comunidade de leitores e escritores. Participar de uma comunidade de leitores [...] envolve o exercício de diversas operações com textos; entre eles e seus autores; entre os próprios autores; entre os autores, os textos e seu contexto. 
No aspecto linguístico, reiteramos a riqueza do texto cordelístico pela presença de traços característicos do povo nordestino que denotam a singularidade e expressividade de uma realidade social. Se, no passado, o cordel ajudou a mediar o ensino da leitura e escrita no nordeste, hoje sua ressignificação em sala de aula auxilia no ensino da língua materna e aproxima os educandos da cultura popular.

Dessa maneira, considerando nossa inserção numa sociedade que estigmatiza padrões sociais pela linguagem, propõe-se a utilização do cordel como uma abordagem insurgente, no sentido de minimizar os preconceitos incutidos a essa variedade linguística, bem como despertar o prazer pela leitura e, consequentemente, à escrita. Isso convoca professores, estudantes e escola a repensar a prática docente de leitura e escrita em seus diversos aspectos e espaços, com especial atenção para a inserção da literatura de cordel no cotidiano escolar. 


\section{REFERÊNCIAS}

BRASIL, Ministério da Educação. Secretaria da Educação Básica. Orientações curriculares para o ensino médio: linguagens códigos e suas tecnologias. Vol.1. Brasília:MEC/SEB,2006. Disponível em: https://sites.google.com/site/revistanovasletras/edicao-2011/orientacoes-curriculares-para-o-ensino-medio-linguagens-codigos-e-suas-tecnologias. Acesso em: 20 de janeiro de 2021.

BRASIL, Diretrizes Curriculares Nacionais Gerais da Educação Básica: MEC, SEB, DICEI, 2013. Disponível em: http://portal.mec.gov.br/busca-geral/323-secretarias-112877938/orgaos-vinculados-82187207/12992-diretrizes-para-a-educacao- . Acesso em: 20 de janeiro de 2021.

BRASIL,Base Nacional Comum Curricular. Brasília: MEC, 2017. Disponível em: http:// basenacionalcomum.mec.gov.br/images/BNC C_20 dez_site.pdf. Acesso em: 22 de dezembro de 2019.

BRASIL,Lei 9.394, de 20 de dezembro de 1996. Estabelece as Diretrizes e Bases da Educação Nacional. Disponível em: http://www.planalto.gov.br/ccivil_03/leis/ L9394. Acesso em: 15 de junho de 2020.

BRASIL, Parâmetros Curriculares Nacionais. Brasília: MEC/SEF, 1998. Disponível em: http://portal.mec.gov.br/seb/arquivos/pdf/introducao . Acesso em: 15 de junho de 2020

BRASIL, Orientações Curriculares para o Ensino Médio: linguagens, códigos e suas tecnologias. Secretaria de Educação. Brasília: MEC, 2008. Disponível em: http:// portal.mec.gov.br/seb/arquivos/pdf/book_volume_01_internet.pdf. Acesso em : 15 de junho de 2020

FREIRE, P. Considerações em torno do ato crítico de estudar. In: FREIRE, P. Ação Cultural para a Liberdade e outros escritos. 6. ed. Rio de Janeiro: Paz e Terra, 1982.

FREIRE, P . Educação como prática da liberdade. Rio de Janeiro, Editora Paz e Terra LTDA, v. 199, 1987.

GALVÃO, Ana Maria Oliveira de. Oralidade, memória e a mediação do outro: praticas de letramento entre sujeitos com baixos níveis de escolarização- o caso do cordel 
(1930-1950) Educação \& Sociedade, vol. 23, núm. 81, dezembro, 2002, p. 115142 Centro de Estudos Educação e Sociedade Campinas, Brasil.

LERNER, D. Ler e escrever na escola: o real, o possível e o necessário. Porto Alegre: Artmed, 2002.

MELO, Veríssimo de. Literatura de Cordel: visão histórica e aspectos principais. In: LOPES Ribamar. (org.). Literatura de Cordel: antologia. Fortaleza: BNB, 1982. MEYER, M. Autores de cordel. São Paulo: Abril Cultural, 1980.

PPP- Projeto político pedagógico da Escola de Ensino Médio Virgílio Távora, 2018.

RIBEIRO, Luís Távora Furtado. Aspectos da Crise econômica e social atual na educação disponível em : https://www.seminariosregionaisanpae.net.br/numerol/ Textos/LuisTavoraA.pdf

SILVA, I.M.M. Literatura em sala de aula: da teoria literária à prática escolar. Anais do Evento PG Letras 30 Anos Vol. I (1): 514-527, 2003.

TODOROV, Tzvetan. A literatura em perigo. Rio de Janeiro: Difel, 2009.

ZILBERMAN, Regina. O papel da literatura na escola. Revista Via Atlântica, UFRGS, No:14, dezembro de 2008. Disponível em: http://www.periodicos.usp.br/ viaatlantica/article/view/50376, acesso em: 14 de junho de 2020. 